Tesis

Año XI, No 10, 2017, 65-78

\title{
EI problema de la seguridad pública: Una aproximación desde la teoría del Estado de Thomas Hobbes
}

\author{
Giancarlo W. Garcés Arce \\ Universidad Nacional Mayor de San Marcos \\ giancarlo-92@hotmail.com
}

\section{Resumen}

Analiza el Estado desde la concepción hobbesiana y precisa que este tiene como principal objetivo garantizar la seguridad en la sociedad política, desplazando otras metas estatales como el bien común, la felicidad, la protección de las libertades, etc. que tuvieron relevancia en los proyectos filosófico-políticos de la tradición clásica y de no pocos filósofos contemporáneos. El Estado hobbesiano resulta mínimo con relación a una posible intervención en ámbitos como el social y el económico, pero expansivo respecto a las medidas para combatir la inseguridad. Propone que este Estado y los contemporáneos de orientación neoliberal están legitimados por su función policial en un escenario internacional marcado por el miedo y la inseguridad.

Palabras clave: Thomas Hobbes, Seguridad, Estado, Estado de naturaleza, Miedo

\begin{abstract}
Analyzes the state from the conception Hobbesian and specifies that it has as its main objective to guarantee the security in the political society, displacing other state goals like the common good, the happiness, the protection of the liberties, etc. that They had relevance in the philosophical-political projects of the classical tradition and of not few contemporary philosophers. The Hobbesian state is minimal in relation to a possible intervention in areas such as social and economic, but expansive with regard to measures to combat insecurity. It proposes that this state and the contemporaries of neoliberal orientation are legitimized by their police function in an international scenario marked by fear and insecurity.
\end{abstract}

Keywords: Thomas Hobbes, Security, State, State of nature, Fear 


\section{EI problema de la seguridad pública: Una aproximación desde la teoría del Estado de Thomas Hobbes}

\section{Introducción}

Cuando la filosofía política moderna empezaba a abrirse paso hacia los siglos XVI y XVII con las siempre tan polémicas figuras de Nicolás Maquiavelo y Thomas Hobbes, una de las cuestiones más importantes que abordó fue la de la problemática de la seguridad en el marco de la teoría del Estado. Es decir, tuvo entre sus principales objetivos determinar mediante qué mecanismos el Estado podía garantizar la seguridad, el orden y la paz en la sociedad. Por supuesto, esta preocupación tuvo su origen en la complicada y turbulenta situación que atravesó Europa en aquella época. Recuérdense los conflictos religiosos y políticos en Inglaterra, el sinfín de disputas bélicas en territorio italiano, el enfrentamiento entre la monarquía francesa y los hugonotes, etc. Por todos estos acontecimientos, los gobernantes de los Estados, las ciudades-Estado y los imperios europeos se preocuparon de manera especial por conseguir la pacificación de sus territorios. Así, filósofos dedicados a la exploración del fenómeno político como Maquiavelo y Hobbes no pudieron ser ajenos a esta preocupación.

A pesar de esta importante coincidencia respecto a la problemática del orden y la seguridad en sus teorías del Estado, es necesario tener en cuenta las insalvables diferencias entre las propuestas de ambos filósofos. Por un lado, el florentino no reduce su reflexión filosófico-política a la idea de que el Estado deba abocarse casi exclusivamente a ser garante de la seguridad en la sociedad, también planteó como una finalidad estatal importante la búsqueda del bien común y la libertad para los hombres en el horizonte de un gobierno republicano. ${ }^{1}$ A diferencia de Hobbes (2010), que define al Estado en los siguientes términos:

[...] es una persona de cuyos actos una gran multitud, por pactos mutuos, realizados entre sí, ha sido instituida por cada uno como autor, al objeto de que pueda

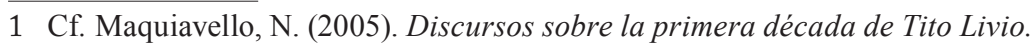


utilizar la fortaleza y medios de todos, como lo juzgue oportuno, para asegurar la paz y defensa común (p.141).

Si bien existen algunos pasajes aislados de los principales escritos políticos del filósofo de Malmesbury en los que se sugiere que las nociones de seguridad y orden no tendrían por qué considerarse de manera tan restringida y limitada, el derrotero general de su filosofía política termina limitando las funciones del Estado a la búsqueda de la pacificación social. Desde esta perspectiva, Hobbes sostiene que una sociedad bien organizada es aquella que simplemente logra conseguir el orden y la seguridad propios de un estado de paz. Por lo que la posibilidad de realizar otras metas políticas como el bien común, la libertad o la felicidad ${ }^{2}$ termina siendo relegada debido al marcado énfasis hecho en la búsqueda de una sociedad meramente pacificada.

El detalle que conviene considerar es que, un escenario político y social como el que sirve a Hobbes para justificar los alcances bastante restringidos de su concepción de la política tiene mucha e importante semejanzas con el que encontramos en nuestras sociedades contemporáneas. Ocurre que las crecientes oleadas de delincuencia común y crimen organizado, así como también los ataques narcoterroristas $\mathrm{y}$ fundamentalistas han generado una alarma de inseguridad en diferentes partes del mundo como consecuencia de la resuelta propagación en la población de un miedo generalizado.

Este nuevo escenario ha traído como consecuencia que en distintas partes del mundo las aspiraciones políticas, económicas y sociales como la lucha contra las desigualdades, la protección de las libertades, la búsqueda de mejores condiciones laborales, etc. hayan quedado notablemente desplazadas en el imaginario social de la ciudadanía.

Por nombrar un caso más puntual, en casi todos los países de Latinoamérica la problemática de la inseguridad ha logrado posicionarse estadísticamente —de acuerdo con una serie de estudios especializados -3 como el principal problema que, desde la perspectiva de la población, el Estado debería resolver por encima de cualquier otro. En definitiva, resulta cada vez más común que las poblaciones de distintas partes del mundo acepten que la función del Estado está vinculada casi exclusivamente a la búsqueda de la seguridad y el orden en un escenario marcado por el miedo. Sin duda, tal escenario remite inmediatamente al planteamiento desarrollado por el filósofo de Malmesbury.

2 No fueron pocos los pensadores de los siglos XVI y XVII que vincularon la función del Estado con metas más audaces que la seguridad. Por lo tanto, no resulta convincente sostener que es inherente a toda filosofía política que aparezca en un contexto signado por los conflictos sociales y políticos el rebajar los alcances de la política.

3 Principalmente la investigación publicada en 2012 por la Corporación Latinobarómetro bajo el título "La Seguridad Ciudadana. El problema principal de América Latina". 
Partiendo de estas consideraciones nuestra estructura argumentativa asume en un primer apartado, cómo es que la noción de seguridad resulta capital en la teoría hobbesiana del Estado; para ello revisa los interesantes matices que se encuentran en los principales escritos políticos de Hobbes - Elementos de Derecho Natural y Político, De Cive y Leviatán - en lo que concierne a los fines del Estado. De este modo evidencia que la seguridad logra posicionarse cada vez más categórica a medida que va consolidándose el proyecto del filósofo de Malmesbury. A partir de lo anterior también se comprenderá cómo su concepto de Estado termina limitando las pretensiones de la acción política.

El segundo apartado intenta establecer un nexo entre el Estado hobbesiano, y la situación de nuestras sociedades contemporáneas; sociedades en las que la violencia, el miedo y la defensa de un Estado mínimo de orientación neoliberal que busca legitimarse exclusivamente en su función pacificadora están más que presentes.

\section{E1 Estado-Leviatán como garante de la seguridad para los súbditos}

El concepto hobbesiano de Estado tiene como punto de partida la conocida hipótesis del estado de naturaleza, la cual presenta al hombre en un escenario remoto y primigenio desde el que se pretende explicar su origen y desarrollo posterior. Por tal motivo, en algunas ocasiones se ha sugerido que esta hipótesis no sería otra cosa que una forma secularizada del mismo término surgido en la Edad Media, y a partir del cual se explicó el origen de la política desde la situación de un individuo en el "Paraíso terrenal" anterior al pecado original (el estado empírico). ${ }^{4}$

Lo cierto es que, partiendo de este marco hipotético, Hobbes da cuenta de un momento prehistórico y prepolítico en el que los seres humanos habrían vivido con plena libertad: sin instituciones, sin conocimiento de ninguna forma de organización y siendo poseedores de las mismas capacidades físicas e intelectuales útiles para la supervivencia (Hobbes, 2000). Ahora bien, el hecho de que la naturaleza haya hecho que los hombres sean vanidosos en extremo, trajo consigo que estos no tardaran en enfrentarse a sus pares para afirmar su superioridad: "en perpetuo estado de desconfianza y estudiando cómo molestarse mutuamente, con lo cual el estado de los hombres en esta libertad natural es el estado de guerra" (Hobbes, 2005, p. 173).

Empero, no obstante que el triunfo sobre los otros fue el principal motivo de felicidad para el hombre natural, llegó un momento en el que se percató de los graves peligros que corría su vida cuando entraba en conflicto con otros hombres. Quizá una herida real o un dolor físico durante tales enfrentamientos, afirma Hobbes, originaron un miedo terrible por la muerte.

4 Cf. Dussel, E. (2007) el capítulo "Thomas Hobbes: el nuevo paradigma del discurso de fundamentación de la política”, en Materiales para una politica de la liberación, pp. 241-254. 
Desde ese momento, el hombre natural se hizo consciente de que su libertad no le servía para contrarrestar la posibilidad de morir de manera violenta. Así, el estado natural terminó siendo una etapa infeliz, miserable, precaria, marcada por el temor y en la cual el hombre no soportó seguir pasando sus días. Significa que el descubrimiento del miedo como la pasión primordial de la naturaleza humana representa la piedra angular de la reflexión política hobbesiana, ya que encaminó a los hombres a la superación del estado de naturaleza y, como consecuencia, al establecimiento de una sociedad política como nueva forma de organización; es decir, el surgimiento del Estado tuvo su origen en el excesivo temor del hombre natural ante una circunstancia en la que el hombre era lobo para el hombre.

A pesar del poder que inicialmente tienen en él, no son los apetitos afirmativos como la vanidad, el impulso de prestigio, la envidia, etc., sino la motivación más conservadora de todas (el miedo) la que impulsa al hombre a salir del estado de naturaleza para lograr una vida más apacible y sin peligros (Strauss, 2011).

Partiendo de esta condición de miedo, Hobbes sugiere — siempre de manera hipotética- que en determinado momento los hombres que vivían en estado de naturaleza confluyeron en una asamblea y decidieron realizar un pacto social para garantizar la seguridad, el orden y la paz de cada uno de ellos. ${ }^{5}$

Ahora bien, el filósofo de Malmesbury considera que lo anterior solo puede lograrse si los hombres renuncian a su derecho natural (aquel que les otorga completa libertad de acción en el estado de naturaleza) en favor de un poder absoluto encargado desde ahora de gobernarlos. Por ello, sostiene lo siguiente sobre el nacimiento de este poder artificial que no es otra cosa que el Estado:

En toda ciudad, de ese hombre o concejo a cuya voluntad cada individuo particular ha sometido su voluntad del modo que ya se ha declarado se dice que tiene el poder supremo, o mando principal, o dominio. Y ese poder y derecho de mandar consiste en esto: en que cada ciudadano ha transferido toda su fuerza y poder a ese hombre o concejo (Hobbes, 2000, p. 119).

Desde la perspectiva hobbesiana, esto también implica que el Estado debe ser concebido como una entidad distinta y separada de todos los hombres particulares, además de poseedora de sus propios derechos y propiedades. ${ }^{6}$ Los ahora súbditos —aunque Hobbes astutamente se refiera algunas veces a ellos como ciudadanos- ${ }^{7}$

5 Para Hobbes el fundamento y fin de la sociedad política es el individuo. Por ello, su filosofía política marcó un derrotero que más tarde sería seguido por el liberalismo de John Locke y que estableció una ruptura con la característica búsqueda del bien común de la tradición clásica.

6 Cf. Skinner, Q. (2003). El nacimiento del Estado.

7 Como menciona Skinner, la audacia de Hobbes le llevó a titular uno de sus escritos políticos más importantes como De Cive (Del ciudadano), a pesar de la evidente carga republicana que subyace en este término. Su objetivo habría sido apoyarse en la considerable aceptación que tenía esta palabra para hacer referencia al hombre que forma parte de una sociedad política, pero sin negar 
están obligados ante una autoridad superior, abstracta e impersonal como es el Estado. De esta forma, Hobbes abandona la perspectiva "carismática" del poder político que, sobre todo, tuvo especial relevancia en la Edad media y en los primeros dos siglos de la modernidad. Así, el Estado se constituye metafóricamente como un Leviatán, una gran máquina útil para garantizar la seguridad de los individuos, por lo que el rol del soberano político — sea una asamblea de hombres o, más convenientemente, un monarca - es el de representar la voluntad del Estado. Las acciones del soberano son solamente las de alguien que representa un papel, pues en sentido estricto es el Estado el que ostenta la soberanía política como persona artificial, cuyo principal objetivo es garantizar la seguridad de los súbditos.

Después de haber comprendido cómo es que se establece la fundación del Estado, corresponde profundizar en la noción de seguridad, tan determinante para comprender la teoría política de Hobbes.

Para comenzar, resulta importante recordar que en la consideración hobbesiana de los fines del Estado que se encuentra en Elementos de derecho natural y politico (1640) y De Cive (1642), todavía se encuentran rezagos de la tradición clásica en la que el filósofo de Malmesbury se había educado. ${ }^{8}$ Así, se presenta en el primero de estos escritos la siguiente afirmación:

La unión así realizada es lo que los hombres llaman hoy día un cuerpo político o sociedad civil; los griegos lo llamaron polis, es decir, ciudad; lo que se puede definir una multitud de hombres unidos como una sola persona, por un poder común, para su paz, defensa y beneficio común (Hobbes, 2005, p. 211).

De la misma manera, una revisión del De Cive nos llevará a no pocos pasajes en los que Hobbes sostiene que entre las funciones del Estado están el propiciar el bien común y la felicidad de los hombres, ${ }^{9}$ asumiendo de esta forma una perspectiva cercana a la de la filosofía política clásica. Sostiene lo siguiente en el mencionado libro:

Por lo tanto, quienes han asumido la administración del poder en un gobierno de esta clase pecarían contra la ley de naturaleza [...] si no procuraran, en la medida en que las leyes lo hiciesen posible, abastecer a sus súbditos abundantemente, no solo de aquellas cosas que son buenas para la vida, sino también de aquellas otras que aumentan el placer (Hobbes, 2000, pp. 212-213).

el hecho de que, en sentido estricto, todo ciudadano debería considerarse súbdito del que ostenta el máximo poder político. Es decir, aunque el título del mencionado libro haga referencia a los ciudadanos, en el Hobbes no hace otra cosa que presentarnos los deberes de los súbditos para con el soberano absoluto.

8 Cf. Strauss, L. (2011). La filosofía política de Hobbes. Su fundamento y su génesis.

9 "Ha de hacerse, pues, algo más: que aquellos que consintieron en buscar la paz y la ayuda mutua en aras del bien común puedan ser, por miedo, refrenados de disentir otra vez cuando sus intereses privados parezcan discrepar del bien común" (Hobbes, 2000, p. 115). 
A pesar de lo anterior, en estos dos escritos políticos anteriores a Leviatán es patente que el objetivo de nuestro autor es empezar a definir el Estado vinculándolo principalmente a la noción de seguridad, pues aquel se presenta ante todo como la entidad artificial que neutraliza la posibilidad de que perezcamos por una acción violenta de otro hombre:

Podemos, pues, definir una ciudad diciendo que es una persona cuya voluntad, por acuerdo de muchos hombres, ha de tomarse como si fuese la voluntad de todos; de tal modo que dicha persona puede hacer uso de todo el poder y de todas las facultades de cada persona particular para mantenimiento de la paz y para defensa común (Hobbes, 2000, pp.118-119).

Ahora bien, la máquina estatal logra un funcionamiento perfecto cuando su soberanía absoluta está garantizada. Y esto solo se puede conseguir cuando todos los hombres renuncian a sus derechos y poderes en favor del soberano político, que, desde la perspectiva de Hobbes, conviene que sea un solo hombre; y es que solo un monarca absoluto puede ser capaz de controlar el ímpetu egoísta de la totalidad de los hombres mediante una disciplina común e infundiéndoles temor a través de su poder absoluto en lo que se refiere a aquellos actos que afectan a la seguridad y la paz.

Cabe recordar que en el estado de naturaleza la inseguridad tenía como causa principal el derecho que los hombres tienen, de manera natural, a hacer uso de su poder para sus fines particulares. Así, el cimiento de la seguridad se encuentra en el compromiso que todos los hombres tienen entre sí para ceder todo su poder y su fuerza a un solo hombre.

Desde esta perspectiva, en Leviatán (1651) —escrito político en el que la seguridad aparece como objetivo estatal con plena independencia de cualquier rezago de la tradición clásica antes mencionada - se nos asegura que la creación del Estado implica lo siguiente:

[...] elegir un hombre o una asamblea de hombres que represente su personalidad; y que cada uno considere como propio y se reconozca a sí mismo como autor de cualquier cosa que haga o promueva quien representa su persona, en aquellas cosas que conciernen a la paz y la seguridad comunes; que, además, sometan sus voluntades cada uno a la voluntad de aquél, y sus juicios a su juicio (Hobbes, 2010, p.140).

Con relación a otras funciones que podría desempeñar el Estado además de las vinculadas a la seguridad, la paz y el orden, Hobbes no se explaya lo suficiente ni desarrolla una reflexión al respecto, pues su preocupación principal es que aquel neutralice la posibilidad de que se desencadene la anarquía en la sociedad.

Por ello, cuando el filósofo de Malmesbury se ocupa, por ejemplo, de la noción de libertad — que para su época estaba siendo desarrollada por teóricos del republicanismo inglés como Milton, Sidney y Harrington, y ya había sido planteada por Nicolás Maquiavelo como uno de los principios que justifican la fundación de una 
sociedad política - no hace otra cosa que definirla como la ausencia de oposición, es decir, de impedimentos externos al movimiento. Recordemos que, desde su perspectiva, la libertad en sentido estricto es dejada de lado desde el momento en que se abandona el estado de naturaleza para conformar la sociedad política. Con lo cual, en el marco de una sociedad política, la libertad solo puede entenderse de manera bastante limitada como libertad de cadenas, libertad para que el cuerpo se desplace sin obstáculos. Una característica de la vida humana que, evidentemente, suele ser garantizada por los gobiernos monárquicos, dirá Hobbes.

Por ello no resulta necesario que la promoción de la libertad de los ciudadanos sea presentada como uno de los fines más importantes del Estado. Sobre todo, si por libertad se entiende el margen de participación política que deberían tener los hombres en tanto que ciudadanos, pues esto se opondría a la soberanía absoluta del gobernante. Según Hobbes, promover la libertad de los ciudadanos en un sentido republicano implicaría otorgarle una parcela de poder a cada uno de estos, trayendo consigo la división de la soberanía y, por tanto, el retorno inmediato al estado de naturaleza.

Este planteamiento hobbesiano supone que la política es una actividad de la que solo se puede ocupar un sector bastante reducido de la sociedad: el gobernante y aquellos que le rodeen. Según Skinner (2010), esta oposición radical entre la idea de libertad desarrollada por los republicanos y la defendida por Hobbes no es casual, pues este habría sido "el enemigo más temible de la teoría republicana de la libertad, y sus intentos por desacreditarla constituyen un verdadero hito en la historia del pensamiento político en lengua inglesa" (p.212).

Sin embargo, el autor de Leviatán parece ceder un poco cuando sostiene que los súbditos pueden hacer libremente muchas cosas con respecto a las cuales la ley permanece en silencio, pero vale precisar que dicho margen puede ser abolido en cualquier momento por el soberano mediante la promulgación de normas restrictivas, pues en la teoría política de Hobbes no existen mecanismos que protejan a los individuos de las posibles arbitrariedades del gobernante.

Sobre una problemática política y social ya analizada para la época de Hobbes como la pobreza, este afirma que los pobres no pueden culpar al Estado por la condición en la que viven, debido a que esta tiene su origen en la ociosidad y el despilfarro característicos de sus estilos de vida (Hobbes, 2000). Por lo que la cuestión de la pobreza continúa el filósofo de Malmesbury, se podrá resolver cuando los hombres que la padecen decidan ser más empeñosos en el trabajo y más frugales en sus costumbres, no cuando el Estado decida intervenir en dicha problemática. ${ }^{10}$

10 A propósito del problema de la pobreza en la Inglaterra del siglo XVII, conviene revisar el Ensayo sobre la ley de pobres de John Locke, donde este filósofo desarrolla una opinión similar a la de Hobbes. 
Así, es evidente que los objetivos del Estado hobbesiano se reducen a la seguridad, el orden y la paz. Otros fines estatales como la consecución de la libertad, la felicidad, el bien común, etc., quedan evidentemente marginados y desplazados. Como acertadamente afirma Leo Strauss, ${ }^{11}$ la filosofía política de Hobbes trae consigo una notable reducción de los niveles de la acción social, pues con ella las metas humanas en política dejan de tener la audacia que, por ejemplo, se encontraba en la filosofía política clásica. ${ }^{12}$

Ahora bien, es necesario considerar que la centralidad que tiene la noción de seguridad en la teoría hobbesiana del Estado mantiene una estrecha relación con la coyuntura social y política de la Inglaterra del siglo XVII. Como ya se ha sugerido, para el filósofo de Malmesbury era importante hacer énfasis en la seguridad, porque el peligro de una anarquía estaba latente debido a los constantes conflictos entre monárquicos y parlamentaristas en su país; actores políticos que ya habían protagonizado la denominada Guerra Civil Inglesa en 1642. Hobbes consideraba que el escenario más trágico y problemático era el de un desorden generalizado en donde la sociedad careciera incluso de un soberano político, lo cual traería como consecuencia inmediata que los hombres regresen al estado de naturaleza.

El detalle es que este peculiar contexto social no justifica el hecho de que se haga de la monarquía absoluta una forma de gobierno válida para cualquier estado de cosas en la sociedad. Es pertinente recordar que otros filósofos, partiendo de una coyuntura parecida a la que vivió Hobbes, han vinculado sus conceptos de Estado a objetivos y metas más audaces, sin abandonar su preocupación por la seguridad y el orden. ${ }^{13} \mathrm{Al}$ respecto, se podría sostener que, si Hobbes piensa en una soberanía absoluta en cualquiera de los escenarios políticos posibles en la sociedad, se debe a que asume una premisa fundamental: el hombre siempre será lobo para el hombre, por ello, se hace indispensable garantizar una intervención política absoluta para aplacar sus ambiciones desmedidas. Sin embargo, aquí cabe preguntarse si la concepción hobbesiana del hombre es la más acertada para comprender la naturaleza de este, habida cuenta de que no considera aspectos como la solidaridad y el cooperativismo.

Dejando de lado las posibles objeciones que se pueden presentar contra el planteamiento político de Hobbes, es importante considerar que su teoría política también resulta un anuncio del concepto de Estado que van a construir posteriormente los representantes del liberalismo con John Locke a la cabeza. Esto porque la pujante burguesía de los siglos posteriores al autor de Leviatán, cada vez que invocó

11 Cf. Strauss, L. (1970). ¿̇Qué es filosofía politica?

12 No es casual que Hobbes dedique un número considerable de páginas de sus escritos políticos a criticar las ideas de filósofos como Platón, Aristóteles y Cicerón, pues consideró que las mismas promovían la sedición al sostener que solo en un gobierno republicano la totalidad de los hombres podría disfrutar de la libertad que les correspondía por naturaleza.

13 El ejemplo paradigmático al respecto es el de la filosofía política de Nicolás Maquiavelo. 
al Estado fue para buscar un garante de la seguridad de sus propiedades, mientras que sospechó de cualquier otra intervención estatal sea esta de índole económica, social o política. Es decir, el burgués, siguiendo el camino trazado por Hobbes, hace del Estado una mera agencia policiaca cuya función principal es la de imponer un poder coercitivo absoluto sobre los que pueden poner en peligro sus intereses económicos. $^{14}$

A propósito de esta novedosa preocupación por la protección de la propiedad privada en las sociedades europeas, Michel Foucault comenta lo siguiente:

[...] en la segunda mitad del siglo XVIII, el proceso tiende a invertirse. En primer lugar, con el aumento general de la riqueza, y también con el gran empuje demográfico, el blanco principal del ilegalismo popular dejan de ser ya en primera línea los derechos para pasar a los bienes: el hurto, el robo tienden a remplazar al contrabando y la lucha armada contra los agentes del fisco. Y, en esta medida, los campesinos, los granjeros y los artesanos resultan ser su víctima principal (2009, pp. 97-98).

Quiere decir que a partir de la teoría política de Hobbes y luego con el liberalismo económico y político el Estado se constituye, ante todo, como garante de la seguridad de los individuos tanto en lo que respecta a sus personas como a sus bienes materiales. Su participación en otros ámbitos se empieza a reducir considerablemente. Ahora bien, esta orientación completamente conservadora en torno a las funciones y objetivos del Estado, lejos de haber sido superada, sigue vigente en nuestras sociedades y últimamente se ha maximizado con la creciente problemática de la inseguridad en distintas partes del mundo. Por lo que los Estados nacionales, o lo que queda de ellos, han desplazado su preocupación hacia la delincuencia común, el crimen organizado, el terrorismo, el narcotráfico, etc., descuidando otras problemáticas sociales también muy importantes.

\section{E1 regreso de Hobbes: hacia un Estado mínimo y vigilante}

Hasta aquí, se ha sustentado la tesis de que el Estado hobbesiano se justifica y legitima casi por completo en sus formas negativas de represión de la violencia y el desorden. Como consecuencia, la propuesta del autor de Leviatán es la de un Estado mínimo con relación a posibles intervenciones en los ámbitos económico y social, pero expansivo en cuanto a su objetivo de garantizar la seguridad y el orden.

Esta forma de comprender la función del Estado en la sociedad guarda ciertas semejanzas con la orientación que han seguido las políticas económicas neoliberales en las últimas décadas con respecto a los alcances del aparato estatal. También defendiendo la mínima participación del Estado en tales ámbitos mencionados y el endurecimiento de las disposiciones estatales en lo que respecta a la problemática

14 Cf. Laski, H. (1961). El liberalismo europeo; también Locke, J. (2011). Ensayo sobre la tolerancia y otros escritos sobre ética y obediencia civil. 
de la inseguridad. Por ello, entre las características más relevantes asociadas al neoliberalismo no solamente se puede contar la retirada del Estado preocupado por la cuestión social, sino también la emergencia de un aparato penal expansivo, intrusivo y proactivo. ${ }^{15}$

Es pertinente recordar que el neoliberalismo, como escuela económica, surgió como una forma de combatir el Estado de bienestar, que tras la Segunda Guerra Mundial logró relativo éxito en Europa y los EE.UU. aplicando políticas económicas de carácter proteccionista y redistributivo; con todas sus falencias y limitaciones, esta forma de organización política y económica, prestó más atención a problemáticas como la pobreza, el desempleo, la discriminación, la educación, las libertades, los derechos laborales, etc. Sin embargo, de un tiempo a esta parte, la creciente influencia del neoliberalismo ha venido desmantelando dichas medidas proteccionistas en los diferentes países de Occidente en los que se implementó, mientras que en la mayor parte de Latinoamérica ha logrado consolidarse sin ninguna oposición importante.

Paralelamente, en los últimos años se ha asistido a un aumento exponencial de la percepción de inseguridad en los ciudadanos de diferentes partes del mundo, ${ }^{16}$ principalmente como consecuencia de la delincuencia común, el crimen organizado, el narcotráfico y el terrorismo de pretexto político o religioso. ${ }^{17}$

Esta situación de zozobra e inestabilidad ha sido aprovechada por los gobiernos de orientación neoliberal para enfatizar cada vez más en una de las tantas funciones que puede cumplir el Estado: la de ser garante absoluto de la seguridad ciudadana.

Por supuesto, para la realización de esta empresa se ha contado con la participación eficaz de diferentes actores: medios de comunicación, encuestadoras, políticos oportunistas, grupos conservadores, intereses económicos, etc. ${ }^{18}$ Esto se hace

15 Cf. Bohm, M. L. (2013). "Políticas de seguridad y neoliberalismo”, en Fernández S., A. (comp.). Crimen, finanzas y globalización.

16 Quizá los atentados del 11 de setiembre de 2001 en Estados Unidos consolidaron esta característica de inseguridad de nuestras sociedades contemporáneas.

17 Se puede considerar el miedo "generado" por los inmigrantes y desplazados de países subdesarrollados que son percibidos en los países desarrollados como una amenaza real para sus intereses vitales, sociales, económicos y culturales.

18 A propósito, es ilustrativa esta lógica: “[...] la delincuencia tiene una cierta utilidad económica-política en las sociedades que conocemos. La utilidad mencionada podemos revelarla fácilmente: cuanto más delincuentes existan más crímenes existirán, cuanto más crimen haya más miedo tendrá la población y cuanto más miedo haya en la población más aceptable y deseable se vuelve el sistema de control policial.

La existencia de ese pequeño peligro interno permanente es una de las condiciones de aceptabilidad de ese sistema de control, lo que explica porque en los periódicos, en la radio, en la televisión, en todos los países del mundo sin ninguna excepción, se concede tanto espacio a la criminalidad como si se tratase de una novedad en cada nuevo día [...]" (Foucault, 1991). 
evidente cuando comparamos los índices de victimización (violencia real) con los de percepción de inseguridad, pues ocurre que en muchos países el grado de victimización no tendría por qué conducir a un miedo tan excesivo por parte de la población, si no fuera por la clara manipulación de los actores mencionados. ${ }^{19}$

Lo que debe destacarse es que los ciudadanos de un sinnúmero de países empiezan a tener la completa certeza de que el Estado debe encauzar sus esfuerzos de manera casi exclusiva hacia la resolución del problema de la inseguridad; ${ }^{20}$ la consecuencia de esto es el descuido de las otras problemáticas sociales que, como en el caso de la educación y el desempleo, tienen incluso una estrecha relación con aquella. Pareciera que el objetivo es que nos quedemos con una versión completamente sesgada y limitada del problema de la inseguridad, una versión como aquella que precisamente defiende la teoría política de Thomas Hobbes: vinculada exageradamente a la represión de la violencia y el desorden a partir de un Estado vigilante y disuasivo que, sin embargo, no se ocupa en sentido estricto de otras problemáticas.

Así, difícilmente se escuchará a algún opinólogo, político o periodista afirmando que el aumento de los índices de delincuencia tiene una estrecha relación con las abismales desigualdades que existen en nuestro continente. ${ }^{21}$ Tampoco se tendrá en cuenta en las estadísticas aquellos delitos que ocurren sin utilización de violencia, como los delitos económicos: fraudes, quiebras, crímenes empresariales y financieros, así como otros delitos generalmente invisibilizados que impactan sobre la población de forma más directa sin necesidad de basarse en la violencia física.

No se quiere negar que la inseguridad sea un problema que necesariamente deba afrontar el Estado; lo que se enfatiza es que el enfoque desde el que se plantea esta cuestión termina limitando y reduciendo las posibilidades de acción de aquel. En definitiva, queda la idea que el Estado debe dedicarse casi exclusivamente a garantizar la seguridad pública. Lo que a su vez también implica asumir un concepto bastante estrecho de los alcances de la actividad política.

Ante estos escenarios, los Estados buscan diferentes mecanismos para ocuparse del creciente miedo y deseo de protección de los ciudadanos. Entre ellos, el gasto en cámaras de vigilancia, armas, vehículos y otros implementos policiales,

19 Cf. Corporación Latinobarómetro. (2012). La seguridad ciudadana. El problema principal de América Latina.

20 Esta es una de las razones más importantes por las que muchos estadounidenses eligieron a Donald Trump como presidente. En plena campaña electoral, él se presentó como el candidato que de llegar a la presidencia iba a garantizar la seguridad, teniendo en cuenta las amenazas internas y externas. En el mismo sentido que el actual presidente estadounidense, aprovechándose de factores como el miedo, la inseguridad y la violencia, están imponiéndose políticos como Marine Le Pen en Francia y Geert Wilders en Holanda, y grupos políticos como PEGIDA en Alemania y Amanecer Dorado en Grecia.

21 Cf. Corporación Latinobarómetro. Ob. Cit. 
la posibilidad de sacar a los militares a las calles, el endurecimiento de las penas leves, etc. Por ejemplo, tras los ataques al semanario satírico Charlie Hebdo en el año 2015 se desplegaron diversos operativos militares en las calles de Europa, siendo la aceptación ciudadana lo más resaltante, considerando el hecho de que tal disposición trajo consigo una importante limitación de los derechos individuales. Por otro lado, en Latinoamérica, debido a diversas campañas, sigue latente y goza de popularidad la idea que salgan las Fuerzas Armadas a las calles para combatir la delincuencia. Estos mecanismos pueden asumirse como distractores considerando que no atacan los verdaderos problemas que están detrás de la escalada de violencia en todo el mundo, especialmente en Latinoamérica.

Este miedo de la ciudadanía, muchas veces propiciado y azuzado, es el que empieza a movilizar políticamente a la sociedad, tal y como lo había imaginado Hobbes en su reflexión sobre la fundación del Estado y la superación de la condición de naturaleza. Pareciera que una cultura del miedo empieza a consolidarse en nuestras sociedades, haciendo que a través de ella la ciudadanía se incline a aceptar sin ninguna oposición, una orientación hobbesiana del Estado. La posibilidad de una intervención positiva por parte de este en el ámbito de la economía parece completamente negada en el marco de las políticas neoliberales.

Esta preocupación política por la seguridad tiende a endurecer el control penal y policial sobre la pequeña delincuencia, mientras que los controles sobre la gran delincuencia (especuladores financieros, banqueros, aristócratas remanentes, etc.), como ya se mencionó, se flexibilizan hasta desaparecer. El nuevo orden económico necesita de una autoridad estatal soberana monopólica y coercitiva para suprimir y contener dislocaciones y resistencias ${ }^{22}$.

En general, se presenta un bombardeo mediático de tal magnitud con relación a la violencia a través de los gobiernos de turno, los medios de comunicación y otros actores importantes, que la opinión pública ha aceptado en algún sentido que los problemas sociales no son tan urgentes.

Se puede concluir que el miedo, el Estado vigilante, la creciente despreocupación por la problemática social son tres elementos cada vez más influyentes en nuestras sociedades contemporáneas y que, al mismo tiempo, coinciden con el proyecto filosófico-político de Hobbes. Esto nos debería llevar a reflexionar sobre la inconveniencia de justificar y legitimar la acción estatal enfocada únicamente al problema de la inseguridad, cuando es evidente el sinfín de problemáticas, incluso más apremiantes y fundamentales, que se tienen que afrontar desde un concepto de la política, verdaderamente justo.

22 Cf. Bohm, M. L. (2013). Ob, cit. 


\section{Referencias}

Bohm, M. L. (2013). "Políticas de seguridad y neoliberalismo”. En: Fernández S., A. (comp.), Crimen, finanzas y globalización, Madrid: Centro de Investigaciones Sociológicas.

Corporación Latinobarómetro (2012). La seguridad ciudadana. El problema principal de América Latina. Banco de datos en línea. Consultado en http://www.latinobarometro.org

Dussel, E. (2007). Materiales para una política de la liberación. México: UANL - Plaza y Valdés Editores.

Foucault, M. (1991). Las redes del poder. Buenos Aires: Editorial Almagesto. Colección Mínima. Recuperado de http://www.catedras.fsoc.uba.ar/heler/foucault.htm.

(2009). Vigilar y castigar. Nacimiento de la prisión. México: Siglo XXI.

Hobbes, T. (2000). De cive. Elementos fllosóficos sobre el ciudadano. Madrid: Alianza Editorial.

- (2005). Elementos de Derecho Natural y Político. Madrid: Alianza Editorial.

- (2010). Leviatán, o la materia, forma y poder de una república eclesiástica y civil. México: FCE.

Laski, H. (1961). El liberalismo europeo. México: FCE.

Locke, J. (2011). Ensayo sobre la tolerancia y otros escritos sobre ética y obediencia civil. Madrid: Biblioteca Nueva.

Maquiavelo, N. (2005). Discursos sobre la primera década de Tito Livio. Buenos Aires: Losada.

Strauss, L. (1970). ¿Qué es filosofía politica? Madrid: Guadarrama.

(2011). La filosofía de Hobbes. Su fundamento y su génesis. Buenos Aires: FCE.

Skinner, Q. (2003). El nacimiento del Estado. Buenos Aires: Gorla.

(2010). Hobbes y la libertad republicana. Bernal: Universidad Nacional de Quilmes Buenos Aires: Prometeo. 